"This document is the Accepted Manuscript version of a Published Work that appeared in final form in Journal of the American Chemical Society, Copyright (0) 2020 American Chemical Society after peer review and technical editing by the publisher. To access the final edited and published work see [insert ACS Articles on Request author- directed link to Published Work, see

https://pubs.acs.org/doi/pdf/10.1021/jacs.9b11935

\title{
Second Coordination Sphere Effects in an Evolved Ru Complex Based on a Highly Adaptable Ligand Results in Rapid Water Oxidation Catalysis
}

Nataliia Vereshchuk ${ }^{1,2}$, Roc Matheu ${ }^{1}$, Jordi Benet-Buchholz ${ }^{1}$, Muriel Pipelier ${ }^{3}$, Jacques Lebreton ${ }^{3}$, Didier Dubreuil $^{3}$, Arnaud Tessier*,3, Carolina Gimbert-Suriñach ${ }^{1}$, Mehmed Z. Ertem ${ }^{*, 4}$ and Antoni Llobet $*, 1,5$

${ }^{1}$ Institute of Chemical Research of Catalonia (ICIQ), Barcelona Institute of Science and Technology (BIST), Avda. Països Catalans 16, 43007 Tarragona, Spain.

${ }^{2}$ Departament de Química Física i Inorgànica, Universitat Rovira i Virgili, Marcel·lí Domingo s/n, 43007 Tarragona, Spain.

${ }^{3}$ Université de Nantes, CNRS, CEISAM, UMR 6230, Faculté des Sciences et des Techniques, 2 rue de la Houssinière, BP 92208, 44322 Nantes, France.

${ }^{4}$ Chemistry Division, Energy \& Photon Sciences Directorate, Brookhaven National Laboratory, Upton, New York, 11973-5000, USA.

${ }^{5}$ Departament de Química, Universitat Autònoma de Barcelona, Cerdanyola del Vallès, 08193 Barcelona, Spain.

Corresponding authors: arnaud.tessier@univ-nantes.fr; mzertem@bnl.gov and allobet@iciq.es 


\section{Abstract}

A new Ru complex containing the deprotonated 2,2':6',2"'-terpyridine,6,6"-diphosphonic acid $\left(\mathrm{H}_{4} \mathrm{tPa}\right)$ and pyridine (py) of general formula, $\left[\mathrm{Ru}^{\prime \prime}\left(\mathrm{H}_{3} \mathrm{tPa}-\kappa-\mathrm{N}^{3} \mathrm{O}\right)(\mathrm{py})_{2}\right]^{+}, \mathbf{2}^{+}$, has been prepared and thoroughly characterized by means of spectroscopic, electrochemical techniques, X-ray diffraction analysis and with DFT calculations. Complex $\mathbf{2}^{+}$, presents a dynamic behavior in the solution that involves the synchronous coordination and the decoordination of the dangling phosphonic groups of the tPa ${ }^{4-}$ ligand. However, at oxidation state IV complex $\mathbf{2}^{+}$, it becomes seven coordinated with the two phosphonic groups now bonded to the metal center. Further, at this oxidation state at neutral and basic $\mathrm{pH}$, the Ru complex undergoes coordination of an exogenous $\mathrm{OH}^{-}$group from the solvent that leads to an intramolecular aromatic $\mathrm{O}$-atom insertion into the $\mathrm{CH}$ bond of one of the pyridyl groups forming the corresponding phenoxo-phosphonate $\mathrm{Ru}$ complex [Ru'II(tPaO- $\kappa$ $\left.\left.\mathrm{N}^{2} \mathrm{O}_{\mathrm{PO}} \mathrm{O}_{c}\right)(\mathrm{py})_{2}\right]^{2-}, 4^{2-}$, where $\mathrm{tPaO}^{5-}$ is 3-hydroxo-[2,2':6',2"-terpyridine]-6,6"-diyl)bis(phosphonate) ligand. This new in situ generated Ru complex, $\mathbf{4}^{2-}$, has been isolated and spectroscopically and electrochemically characterized. In addition, a crystal structure has been also obtained using single crystal X-ray diffraction techniques. Complex $4^{2-}$ turns out to be an exceptional water oxidation catalyst achieving record high $T O F_{\max }$ in the order of $16,000 \mathrm{~s}^{-1}$. A mechanistic analysis complemented with DFT calculations has also been carried out showing the critical role of intramolecular second coordination sphere effects exerted by the phosphonate groups in lowering the activation energy at the rate-determining step.

\section{Keywords}

Water oxidation catalysis, Ru complexes, water splitting, redox properties transition metal complexes 


\section{Introduction}

Molecular water oxidation catalysis is a field that has been rapidly developing over the last decade mainly due to their potential application in new energy conversion schemes based on water splitting with sunlight. ${ }^{1-7}$ In particular, Ru complexes have been leading the field and today the amount of information extracted from these complexes has generated a deep understanding of the different parameters involved in the catalytic cycle. ${ }^{8,9}$ This has been possible thanks to the spectroscopic characterization of the reaction intermediates as well as due to the kinetic characterization of the different steps involved and complemented with a thorough computational analysis. ${ }^{10-13}$ This wealth of information based on Ru complexes as water oxidation catalysts (WOCs) has also been extended to other transition metals as well as oxides reported as WOCs for their design and mechanistic proposals. ${ }^{14-17}$

The best WOCs known today are based on the Flexible Adaptative Multidentate Equatorial (FAME) ligands ${ }^{18}$ containing polypyridyl carboxylate groups such as $\mathrm{H}_{2} \mathrm{tda}^{19}$ and $\mathrm{H}_{2}$ bda ${ }^{20-22}$ (see Chart I for the drawings of the ligands) and their related derivatives where the carboxylate groups have been partially or totally substituted by phosphonate groups. ${ }^{23-26}$ In particular, the complex [Ru IV $\left.^{\mathrm{I}} \mathrm{OH}\right)(\mathrm{tda}-$ $\left.\left.\kappa-\mathrm{N}^{3} \mathrm{O}\right)(\mathrm{py})_{2}\right]^{+}$(py for pyridine), $\mathbf{1}^{+}$, has been recently shown to achieve $T O F_{\max }$ of $8,000 \mathrm{~s}^{-1}$ at $\mathrm{pH}$ 7.0. ${ }^{19}$ Further, the analysis of its performance shows a delicate balance among multiple equilibria at different oxidation states with diverse coordination number and degree of hydrogen bonding that is responsible for its performance as a catalyst. ${ }^{19,27}$ Because of these delicate equilibria, the replacement of carboxylate groups in $\mathrm{H}_{2}$ tda by phosphonate groups leading to the $\mathrm{H}_{4} \mathrm{tPa}$ ligand (Chart I), is expected to generate significant differences in its catalytic behavior. The electronic nature and geometry of the phosphonate with regard to those of the carboxylate group as well as an increase in steric will be responsible for the different catalytic behavior of the new Ru complexes based on $\mathrm{H}_{4} \mathrm{tPa} .{ }^{28}$ In addition, the increased number of acidic protons with substantially different $\mathrm{p} K_{\mathrm{a}}{ }^{\prime} \mathrm{s}$ are expected to not only facilitate remote proton-coupled electron transfer (PCET) events during redox leveling, ${ }^{29-35}$ but also give rise to beneficial second sphere coordination effects such as hydrogen bonding interactions. Further, the phosphonate groups are expected to act as an intramolecular proton acceptor, at the $\mathrm{O}-\mathrm{O}$ bond formation step, significantly reducing its activation energies.

Here on we present a new family of Ru complexes derived from the $\mathrm{H}_{4} \mathrm{tPa}$ ligand together with a thorough characterization of their redox and water oxidation catalytic properties. 


\section{Results}

\subsection{Synthesis and structure of the precursor complex $\mathbf{2}^{+}$}

The synthesis of the $\mathrm{H}_{4} \mathrm{tPa}$ ligand was carried out in three steps using $2,2^{\prime}: 6^{\prime}, 2^{\prime \prime}$-terpyridine (trpy) as the starting material as described in the supporting information. Initially, the trpy ligand is oxidized to $2,2^{\prime}: 6^{\prime}, 2^{\prime \prime}$-terpyridine-1,1"-dioxide using metachloroperbenzoic acid. The treatment of the latter with $\mathrm{POEt}_{3}$ forms tetraethyl 2,2':6',2"-terpyridine-6,6"-diphosphonate that is hydrolyzed with trimethylbromosilane yielding the $\mathrm{H}_{4} \mathrm{tPa}$ ligand. The synthetic strategy for the preparation of the complexes described in this work is outlined in Figure 1. Complex $\left[\mathrm{Ru}^{\prime \prime}\left(\mathrm{H}_{3} \mathrm{tPa}-\kappa-\mathrm{N}^{3} \mathrm{O}\right)(\mathrm{py})_{2}\right]^{+}, \mathbf{2}^{+}$, is prepared by refluxing stoichiometric amounts of $\mathrm{H}_{4} \mathrm{tPa}$ and $\left[\mathrm{Ru}(\mathrm{dmso})_{4} \mathrm{Cl}_{2}\right]$ in $n$ - $\mathrm{BuOH}$, followed by addition of an excess of pyridine and further refluxing overnight. Proper column chromatography in silica generates pure $2 \mathrm{Cl}$ in moderate yields where the equatorial $\mathrm{H}_{3} \mathrm{tPa}^{-}$ligand acts in a monoanionic fashion. Crystals of $2 \mathrm{PF}_{6} \cdot 3 \mathrm{H}_{2} \mathrm{O}$ sufficiently good for $\mathrm{X}$-ray analysis were obtained by counteranion exchange crystallization from an acidic aqueous solution of $2 \mathrm{Cl}$ and $\mathrm{KPF}_{6}$. The ORTEP view of its solvated cationic moiety is presented in Figure 1. The Ru(II) center features an octahedral type of geometry where the $\mathrm{H}_{3} \mathrm{tPa}^{-}$ligand coordinates in the equatorial plane in a $\kappa-\mathrm{N}^{3} \mathrm{O}$ fashion leaving a dangling non-coordinated phosphonic acid group. The octahedral geometry is completed with two pyridyl groups in the axial position. The bonding parameters are unremarkable ${ }^{36}$ except for distortion due to the geometrical constraints of the $\mathrm{HtPa}^{3-}$ ligand at the equatorial zone, which produces an N-Ru-O angle of $115^{\circ} ; 25^{\circ}$ larger than the ideal $O_{\mathrm{h}}$ geometry. The same angle for the [Rull(tda)(py $)_{2}$ ] is $125^{\circ}, 1^{19}$ that is $10^{\circ}$ higher which is a consequence of the different bonding parameters associated with the phosphonate and carboxylate moieties. ${ }^{28,37}$ Finally, there are three $\mathrm{H}_{2} \mathrm{O}$ molecules in the unit cell, interacting with the phosphonic groups by hydrogen bonding as can be observed in Figure 1. Density functional theory (DFT) calculations at the M06 level of theory ${ }^{38}$ in conjunction with SMD aqueous continuum solvation model ${ }^{39}$ (see computational methods for further details) have been carried out in order to complement the experimental work described here for $\mathbf{2}^{+}$. The computed structure for $\mathbf{2}^{+}$shows a very good agreement with the experimental structure in terms of bonding parameters (Figure S62) revealing its good degree of reliability.

Addition of two equivalents of $\mathrm{Ce}(\mathrm{IV})$ generates the corresponding seven coordinated $\mathrm{Ru}(\mathrm{IV})$ complex $\left[\mathrm{Ru}^{\mathrm{IV}}\left(\mathrm{tPa}-\mathrm{K}-\mathrm{N}^{3} \mathrm{O}^{2}\right)(\mathrm{py})_{2}\right], 3$, where the $\mathrm{PPa}^{4-}$ ligand now acts in a pentadentate manner and the metal center possesses a pentagonal bipyramidal geometry as can be observed in the computed 
structure shown in Figure 1. This complex is diamagnetic at room temperature (RT) with a high field low spin $d^{4}$ electronic configuration, $\left(\boldsymbol{e}_{1}{ }^{\prime \prime}\right)^{4}\left(\boldsymbol{e}_{2}\right)^{0}\left(\boldsymbol{a}_{1}\right)^{0}$, analogous to related $\mathrm{Ru}(\mathrm{IV})$ complexes. ${ }^{19,40,41}$. Its ${ }^{1} \mathrm{H},{ }^{13} \mathrm{C}$, and ${ }^{31} \mathrm{P}$ NMR are presented in the SI see Figures S27-29.

\subsection{Spectroscopy and dynamic behavior of 2}

The spectroscopic properties were investigated by means of UV-vis and NMR spectroscopy. The UVvis spectra of $\left[\mathrm{Ru}^{\prime \prime}\left(\mathrm{H}_{2} \mathrm{tPa}-\kappa-\mathrm{N}^{3} \mathrm{O}\right)(\mathrm{py})_{2}\right], \mathbf{2}$, and its one and two-electron oxidized species $\left[\mathrm{Ru} \mathrm{u}^{\prime \prime \prime}\left(\mathrm{H}_{2} \mathrm{tPa}-\right.\right.$ $\left.\left.\kappa-\mathrm{N}^{3} \mathrm{O}\right)(\mathrm{py})_{2}\right]^{+}$and $\left[\mathrm{Ru}^{\mathrm{IV}}\left(\mathrm{HtPa}-\kappa-\mathrm{N}^{3} \mathrm{O}^{2}\right)(\mathrm{py})_{2}\right]^{+}$were generated via redox titration using $\mathrm{Ce}(\mathrm{IV})$ as the oxidant at pH 1.0 in aqueous triflic acid (Figures S45-S46). Complex 2 is a diamagnetic low spin $\mathrm{d}^{6}$ ion with a typical $\left(t_{2 \mathrm{~g}}\right)^{6}\left(e_{\mathrm{g}}\right)^{0}$ electronic configuration and its NMR spectra and assignment are presented in the Figure 2 and the supporting information (Figures S12-S26 and Figures S35-S36). At room temperature, the NMR spectrum displays eight resonances as if the complex had $C_{2 v}$ symmetry. However, at low temperature, the resonances of the protons $H_{a}, H_{b}, H_{c}$ and $H_{e}$ split indicating the presence of dynamic behavior (Figure 2). The dynamic behavior is associated with the synchronic coordination and decoordination of the dangling phosphonate that has an activation energy of $13.3 \mathrm{kcal} / \mathrm{mol}$ based on Eyring plots generated from VT-NMR (Scheme S2). By computational methods, an estimate activation energy of $7.9 \mathrm{kcal} / \mathrm{mol}$ (see Figure S37) was obtained for this dynamic behavior in line with the experimental observations. The value of the activation energy is similar to that measured for Ru-bda complexes involving coordination and decoordination of the dangling carboxylates. ${ }^{42}$

\subsection{Redox properties of 2}

The redox properties of $\mathbf{2}$ were investigated by electrochemical techniques in a three-electrode cell using glassy carbon as a working electrode and all potentials were measured using a $\mathrm{Hg} / \mathrm{Hg}_{2} \mathrm{SO}_{4}$ as a reference electrode and converted to vs NHE by adding $0.65 \mathrm{~V}$ to the measured potential. Cyclic Voltammetry of $\mathbf{2}$ were performed in aqueous solution as a function of $\mathrm{pH}$ that produces a different degree of protonation at the phosphonate groups. Cyclic voltammetry at pH 7.0 is shown in Figure 3 (red trace) where two chemically reversible and electrochemically quasireversible redox processes can be observed. The first redox process at $E_{1 / 2}=0.83 \mathrm{~V}$ is assigned to a PCET process to generate $\left[\mathrm{Ru}^{\prime \prime \prime}\left(\mathrm{tPa}-\kappa-\mathrm{N}^{3} \mathrm{O}^{2}\right)(\mathrm{py})_{2}\right]^{-}$whereas the second wave at $E_{1 / 2}=0.92 \mathrm{~V}$ is due to a one-electron oxidation

process to form $\left[\mathrm{Ru}^{\mathrm{IV}}\left(\mathrm{tPa}-\kappa-\mathrm{N}^{3} \mathrm{O}^{2}\right)(\mathrm{py})_{2}\right]$. The one-electron nature of the two processes is corroborated by the spectrophotometric redox titration (Figure S45-S46), and the degree of 
protonation is deduced from the Pourbaix diagram shown in Figure 3 right. (see SI for the equations used for the simulation).

The four protons potentially available from the two phosphonic groups in $\mathbf{2}$, allow obtaining a rich family of complexes depending on the degree of oxidation and protonation as shown in the Pourbaix diagram. The $\mathrm{p} K_{\mathrm{a}}{ }^{\prime} \mathrm{s}$ coincide with the dashed vertical lines and are deduced from the change of slope in the $E^{\circ} v s . \mathrm{pH}$ plot. The first and second $\mathrm{p} K_{a}^{\prime}$ 's due to the monodeprotonation of each phosphonic group are expected to occur below $\mathrm{pH} 1.0 . .^{43-45}$ Further, the $p K_{a}$ for the third and fourth proton loss are labeled, $\mathrm{p} K_{\mathrm{a}}$ and $\mathrm{p} K_{\mathrm{a}^{\prime}}$, and are defined in equations 1 and 2 respectively,

$$
\begin{aligned}
& {\left[\mathrm{Ru}^{\prime \prime}\left(\mathrm{H}_{2} \mathrm{tPa}-\kappa-\mathrm{N}^{3} \mathrm{O}\right)(\mathrm{py})_{2}\right]_{(\text {aq })} \rightarrow\left[\mathrm{Ru}^{\prime \prime}\left(\mathrm{HtPa}-\kappa^{-} \mathrm{N}^{3} \mathrm{O}\right)(\mathrm{py})_{2}\right]^{-}{ }_{(\text {aq })}+\mathrm{H}^{+}{ }_{(\mathrm{aq})} \quad p K_{\mathrm{a}}}
\end{aligned}
$$

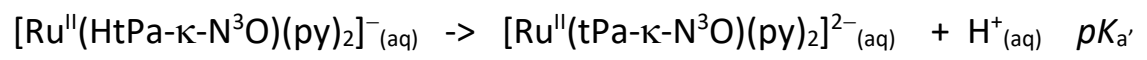

The latter have been independently calculated via spectrophotometric acid-base titration as shown in Figure S47. It is interesting to see how due to the different proton content of the species involved at a given $\mathrm{pH}$, the difference between the IV/III-III/II redox couples changes considerably as a function of $\mathrm{pH}$ as can be graphically observed in Figure S49A. Indeed, at $\mathrm{pH} 7.0$ this difference is only $100 \mathrm{mV}$ but it increases up to $330 \mathrm{mV}$ at pH 13.0 (Figure S49B).

\subsection{Generation of the active Ru species via O-atom insertion}

The synthesis of the active catalyst $\left[\mathrm{Ru}^{\prime \prime \prime}\left(\mathrm{tPaO}-\kappa-\mathrm{N}^{2} \mathrm{O}_{\mathrm{P}} \mathrm{O}_{c}\right)(\mathrm{py})_{2}\right]^{2-}, \mathbf{4}^{2-}$, (see a drawing of the $\mathrm{H}_{5} \mathrm{tPaO}$ ligand in Chart 1; $\mathrm{O}_{\mathrm{p}}$ refers to oxygen atom coordinated to the Ru center via the oxygen atom from the phosphonic group and $\mathrm{O}_{c}$ from the pyridyl group) was carried out electrochemically using $\left[\mathrm{Ru}^{\prime \prime}\left(\mathrm{H}_{3} \mathrm{tPa}-\kappa-\mathrm{N}^{3} \mathrm{O}\right)(\mathrm{py})_{2}\right]^{+}, \mathbf{2}^{+},\left(\mathbf{2}^{+}\right.$is predicted to convert to $\mathbf{2}$ at $\left.\mathrm{pH} 7.7\right)$ as a precursor as outlined in Figure 1.

A sample of $\mathbf{2}^{+}$is dissolved in a pH 7.7 aqueous phosphate buffer solution and placed in a twocompartment electrochemical cell using a Pt mesh as a working electrode. Then a potential of 1.30 $\mathrm{V}$ is applied for 110 minutes. During this process, the initial $\mathbf{2}^{+}$precursor complex is quantitatively transformed into the final complex $\mathbf{4}^{\mathbf{2}}$, where an $\mathrm{O}$ atom insertion between the $\mathrm{Ru}$ center and one of the pyridyl groups takes place. This is reminiscent of the reactivity of dinuclear dicopper 
complexes at low oxidation states with dioxygen reported earlier. ${ }^{46}$ One electron reduction of $\mathbf{4}^{\mathbf{2 -}}$ yields the diamagnetic $4^{3-}$ complex that was characterized by ${ }^{1} \mathrm{H},{ }^{13} \mathrm{C}$, and ${ }^{31} \mathrm{P}$ NMR spectroscopy and whose spectra are shown in the (Figure S39-S44). Electrochemically only the initial and final species are detected (Figure S50).

Single crystals of $4^{3-}$ were obtained by adding excess $\mathrm{Cs}^{+}$to a solution of $4^{2-}$ in $\mathrm{MeOH}$. A crystal structure of $\mathbf{4}^{\mathbf{3}-}$ is displayed in Figure 1 showing the phenoxide bonding and the decoordination of the initial pyridyl-phosphonic group. The complex was further characterized by UV-vis spectroscopy using an Optically Transparent Thin-Layer Electrochemical (OTTLE) cell (Figure S48).

In order to get further insight into the potential sequence of reactions that generate $\mathbf{4}^{\mathbf{2}-}$ from $\mathbf{2}$ (2 converts to 2 at $\mathrm{pH} 7$ according to the Pourbaix diagram) a computational analysis was carried out and the results obtained are summarized in Scheme 1. As the current flows at an applied potential of $1.30 \mathrm{~V}$, the initial $\mathrm{Ru}(\mathrm{II})$ complex $\mathbf{2}^{+}$is initially converted to seven coordinate (CN7) Ru(IV) species, $\left[\mathrm{Ru}^{\mathrm{IV}}\left(\mathrm{tPa}-\kappa-\mathrm{N}^{3} \mathrm{O}^{2}\right)(\mathrm{py})_{2}\right], 3$, in agreement with its redox properties described in the previous section. This complex then reacts with a water molecule with concomitant proton release inducing the decoordination of one of the pyridyl phosphonate groups to generate $\left[\mathrm{Ru}^{\mathrm{IV}}(\mathrm{O})\left(\mathrm{HtPa}-\kappa-\mathrm{N}^{2} \mathrm{O}\right)(\mathrm{py})_{2}\right]^{-}$. The latter then undergoes a PCET step to form $\left[\mathrm{Ru}^{\mathrm{V}}(\mathrm{O})\left(\mathrm{tPa}-\kappa-\mathrm{N}^{2} \mathrm{O}\right)(\mathrm{py})_{2}\right]$. This species is responsible for the intramolecular hydroxylation of the dangling pyridyl group that is highly favored from a thermodynamic perspective $\left(\Delta G=-9.0 \mathrm{kcal} / \mathrm{mol}\right.$ ) and that finally leads to pure $4^{2-}$ following a deprotonation event $(\Delta G=-54.6 \mathrm{kcal} / \mathrm{mol})$. A transition state for the electrophilic oxygen insertion into the $\mathrm{CH}$ bond has also been located with the low free energy of activation $\left(\Delta G^{\ddagger}\right)$ of $14.0 \mathrm{kcal} / \mathrm{mol}$.

The redox and electrocatalytic properties of $4^{2-}$ were investigated by CV and Coulombimetric techniques. Figure 3 (black trace, left) shows the $\mathrm{CV}$ of $4^{2-}$ at $\mathrm{pH} 7.0$ phosphate buffer solution where an electrochemically and chemically reversible wave appears at $E_{1 / 2}=0.35 \mathrm{~V}$ that is assigned to the $\mathrm{Ru}(\mathrm{III}) / \mathrm{Ru}(\mathrm{II})$ couple. At higher anodic potentials a very large electrocatalytic current is observed at approximately $1.4 \mathrm{~V}$ that is due to the oxidation of water to dioxygen. This second wave is associated with a two-electron process and oxido coordination, reaching the $R u(V)=O$ species that is responsible for the reaction with solvent water and $\mathrm{O}-\mathrm{O}$ bond formation. A two-electron process is proposed since no other waves are observed besides the III/II wave and the corresponding $\mathrm{Ru}(\mathrm{IV})=\mathrm{O}$ species are not sufficiently reactive for fast water oxidation and further supported by DFT. 


\subsection{Water oxidation catalysis and mechanisms}

Kinetic characterization of the electrocatalytic water oxidation reaction was carried out for $\mathbf{4}^{2-}$, based on Foot of the Wave Analysis (FOWA) $)^{47-49}$ at $\mathrm{pH} 7.2$ as shown in Figure S54. A TOF $\max =1.610^{4}$ $\left( \pm 0.2 \cdot 10^{4}\right) \mathrm{s}^{-1}$ is obtained that is found to be independent of catalyst concentration between 0.5 and $3.0 \mathrm{mM}$. This first order kinetics behavior with regard to catalyst concentration points towards a water nucleophilic attack (WNA) ${ }^{50}$ type of mechanism where the O-O bond formation between the $\mathrm{Ru}(\mathrm{V})=\mathrm{O}$ species and the solvent is the rate-determining step (rds). This is further supported by theoretical calculations as will be shown in the next section. The performance of $4^{2-}$ as WOC was further tested by a bulk electrolysis experiments described in detail in the supporting information (Figure S53). More than 42 million turnovers with Faradaic efficiencies above 93\%. were obtained using Saveant's methodology that takes into account the concentration of the catalyst close to the electrode surface and manifests the remarkable stability of this catalyst. ${ }^{21-23}$ It is also interesting to point out here that catalyst $\mathbf{4}^{\mathbf{2}}$ is also active at lower $\mathrm{pH}$ albeit with lower efficiency (Figure S51).

A thorough mechanistic analysis was also carried out based on theoretical calculations and is summarized in Figure 4 top, where the different reaction intermediates and the computed $\Delta G$ s and redox potentials associated with each step are presented (see computational methods in the SI for further details). We propose that once the $\mathrm{Ru}(\mathrm{III})$ complex, $\mathbf{4}^{2-}$, is generated, water coordination together with a two-electron oxidation process proceeds to form $\mathrm{Ru}^{\mathrm{V}}=\mathrm{O}$ species, $\left[\mathrm{Ru}^{\mathrm{V}}(\mathrm{O})(\mathrm{HtPaO}-\kappa-\right.$ $\left.\left.\mathrm{N}^{3} \mathrm{O}_{p}\right)(p y)_{2}\right]^{-}$, which will, in turn, react with a solvent $\mathrm{H}_{2} \mathrm{O}$ to generate the corresponding hydroxoperoxido derivative, as indicated in the equation below,

$\left[\mathrm{Ru}^{\mathrm{V}}=\mathrm{O}\right]_{(\mathrm{aq})}+\mathrm{H}_{2} \mathrm{O}_{(\mathrm{l})} \rightarrow\left[\mathrm{Ru}-\mathrm{O}---\mathrm{OH}_{2}\right]^{\ddagger} \rightarrow\left[\mathrm{Ru}^{\mathrm{III}}-\mathrm{OOH}\right]_{(\mathrm{aq})}+\mathrm{H}^{+}(\mathrm{aq})$

The optimized TS for WNA reaction is presented in Figure 4 bottom. It is interesting to realize here that the coordination number $(\mathrm{CN})$ for the $\mathrm{Ru}(\mathrm{V})$ species is 6 with the $\mathrm{tPaO}^{5-}$ ligand acting in a $\mathrm{\kappa}-\mathrm{N}^{2} \mathrm{O}_{\mathrm{c}}$ fashion and thus with a dangling phosphonate group. This dangling group is strategically situated so that it can act as an intramolecular proton acceptor to facilitate the WNA TS and to reduce the activation free energy $\left(\Delta G^{\ddagger}=22.1 \mathrm{kcal} / \mathrm{mol}\right)$. Once $\mathrm{Ru}(\mathrm{III})-\mathrm{OOH}$ is formed then it suffers a PCET that forms the Ru(IV)-OO that spontaneously evolves dioxygen and generates the initial Ru(II) species 
completing the catalytic cycle. The computed $\Delta G^{\ddagger}$ of $22.1 \mathrm{kcal} / \mathrm{mol}$ for the proposed rate-limiting WNA step is relatively high compared to experimental TOF of $16,000 \mathrm{~s}^{-1}$ so we further performed calculations at both M06 and M06-L ${ }^{51}$ level of theories with additional explicit water molecules to account for hydrogen bonding effects from the solvent (Table S4). The computed $\Delta G^{\ddagger} s$ exhibit notable decrease with additional water molecules and with four explicit water molecules the computed activation free energies are 18.7 and $16.3 \mathrm{kcal} / \mathrm{mol}$ at $\mathrm{M} 06$ and $\mathrm{M} 06-\mathrm{L}$ level of theories respectively. We also considered $\mathrm{O}-\mathrm{O}$ bond formation between $\mathrm{Ru}(\mathrm{V})=\mathrm{O}$ species and an oxygen atom of the dangling phosphonate group similar to the oxide relay mechanism recently proposed for Ru-tda complex by Zhan et al ${ }^{52}$ and located a TS structure featuring a $\Delta G^{\ddagger}$ of $13.2 \mathrm{kcal} / \mathrm{mol}$ but the resulting Ru-O-O-P species is uphill by $6.3 \mathrm{kcal} / \mathrm{mol}$ indicating that reverse step has a much lower $\Delta G^{\ddagger}$ of $6.9 \mathrm{kcal} / \mathrm{mol}$. Moreover, at $\mathrm{pH} 7$, nucleophilic addition of $\mathrm{OH}^{-}$to $\mathrm{P}$ atom of Ru-O-O-P moiety similar to that proposed in the oxide relay mechanism is very unlikely and $\mathrm{H}_{2} \mathrm{O}$ molecule should behave as the nucleophile for the hydrolysis of the Ru-O-O-P group, which is expected to result in higher activation energies. A future direction of our studies will be devoted to a closer inspection of WNA and alternative O-O bond formation pathways with full atomistic solvation models."

\section{Discussion}

Detailed understanding of water oxidation catalysis is challenging due to a large number of reactions and intermediates involved in this complex process. The electronic demands imposed by the reaction intermediates accessed at each oxidation state at the different stages of the catalytic cycle involve a change in metal coordination number. Along this line, high oxidation states will prefer hard base ligands while lower oxidation states will prefer softer ones. Additional complexity arises because of the variety of reactions handled by the catalyst including outer-sphere electron transfers (OSET), PCET and chemical reactions that might not necessarily involve ET such as proton transfer or $\mathrm{O}-\mathrm{O}$ bond formation. Moreover, non-desired pathways that derail these reactions from the catalytic cycle towards non-productive or decomposition products also need to be understood, ${ }^{53}$ to be able to avoid them and to obtain robust water oxidation catalysts. To control all the parameters indicated above, each step should occur with an activation barrier as low as possible so that efficient water oxidation catalysis can take place.

\subsection{Geometrical and electronic consequences due to the presence of the phosphonate groups}


Complex $\left[\operatorname{Ru}^{\mathrm{IV}}(\mathrm{O})(\mathrm{tda})(\mathrm{py})_{2}\right], \mathbf{1}$, is an example of a catalyst that complies with the above requirements and up to now appears as the fastest water oxidation catalyst ever reported. ${ }^{54}$ The structural consequences of changing carboxylate by phosphonates can be graphically observed by comparing the structures of the diamagnetic seven coordinated catalyst precursors [Ru ${ }^{\mathrm{IV}}(\mathrm{tda}-\kappa-$ $\left.\left.\mathrm{N}^{3} \mathrm{O}^{2}\right)(\mathrm{py})_{2}\right]^{2+}$ and $\left[\mathrm{Ru}^{\mathrm{IV}}\left(\mathrm{tPa}-\kappa-\mathrm{N}^{3} \mathrm{O}^{2}\right)(\mathrm{py})_{2}\right]$ (Figures $\mathrm{S} 61$ and $\mathrm{S} 63$ ). While the X-ray structure of $\left[\mathrm{Ru}^{\mathrm{IV}}\left(\mathrm{tda}-\kappa-\mathrm{N}^{3} \mathrm{O}^{2}\right)(\mathrm{py})_{2}\right]^{2+}$ shows all the coordinating atoms of the tda ${ }^{2-}$ ligand nearly on the equatorial plane, the coordinating oxygen atoms of the phosphonate in $\left[\mathrm{Ru}^{\mathrm{IV}}\left(\mathrm{tPa}-\kappa^{-}-\mathrm{N}^{3} \mathrm{O}^{2}\right)(\mathrm{py})_{2}\right]$ complex are significantly off the equatorial plane as observed in the computed structure shown in Figure 1. Furthermore, this distortion also breaks the planarity of the trpy moiety of the tPa- ligand diminishing the aromatic $\pi$ delocalization. This distortion is due mainly to the different geometric parameters of the phosphonic acid group (pseudo $T_{\mathrm{d}}$ ) as compared to the carboxylate (pseudo $C_{2 \mathrm{v}}$ ), and results in weaker Ru-O bonds for the phosphonic complex. From an electronic perspective the phosphonate group acts as a stronger sigma donor than the carboxylate, leading in general to lower redox potentials and higher $p K a\left(p K_{a}^{\prime} s\right.$ are 3 and 11 for $\left[R u^{\prime \prime}\left(H_{2} t P a\right)(p y)_{2}\right]$ and 6.4 for $\left.\left[\mathrm{Ru}^{\prime \prime \prime}(\mathrm{HtPa})(\mathrm{py})_{2}\right]\right) .{ }^{27}$ The existence of a range of $\mathrm{p} K_{\mathrm{a}}$ values obtained at different oxidation states from the auxiliary ligands is interesting because it can promote remote PCET, that is a PCET where the proton is not associated with the $\mathrm{Ru}-\mathrm{OH}_{2}$ or $\mathrm{Ru}-\mathrm{OH}$ group, but from auxiliary ligands such as the phosphonic ones. This is important because for typical polypyridyl Ru-aqua complexes such as $\left[\mathrm{Ru}(\mathrm{trpy})(\mathrm{bpy})\left(\mathrm{H}_{2} \mathrm{O}\right)\right]^{2+}, 55$ the complex can access $\mathrm{Ru} \mathrm{IV}^{\mathrm{V}}=\mathrm{O}$ species by two consecutive PCET processes from its aqua derivatives but access to reactive $\mathrm{Ru}(\mathrm{V})$ occurs as an ET only process and therefore requires high energy input and overpotential $\left(1.8 \mathrm{~V}\right.$ for $\left.\left[\mathrm{Ru}(\operatorname{trpy})(\mathrm{bpy})\left(\mathrm{H}_{2} \mathrm{O}\right)\right]^{2+}\right) .{ }^{56-58}$ Thus, the possibility to reach $\mathrm{Ru}(\mathrm{V})$ via three PCET processes can open up access to a highly active $\mathrm{Ru}^{\mathrm{V}}=\mathrm{O}$ species at much lower overpotentials.

\subsection{The importance of the second coordination sphere effects}

The two electrons oxidation of the octahedral $\left[R u^{\prime \prime}\left(\mathrm{H}_{2} \mathrm{tPa}-\kappa-\mathrm{N}^{3} \mathrm{O}\right)(\mathrm{py})_{2}\right], \mathbf{2}$, complex generates the CN7 diamagnetic $\left[\mathrm{Ru}^{\mathrm{IV}}\left(\mathrm{tPa}-\kappa-\mathrm{N}^{3} \mathrm{O}^{2}\right)(\mathrm{py})_{2}\right]$. Here the importance of ligand flexibility and design is manifested by leaving a non-coordinated dangling phosphonic acid group at oxidation state II where the Ru complex needs to be CN6. The ligand flexibility also allows for a dynamic behavior where the phosphonic groups synchronically coordinate and decoordinate fast at room temperature. Upon reaching $\mathrm{Ru}(\mathrm{IV})$ the dangling group coordinates thanks to the flexibility of the ligands achieving CN7. At oxidation state IV in basic solution, $\left[\mathrm{Ru}^{\mathrm{IV}}\left(\mathrm{tPa}-\kappa-\mathrm{N}^{3} \mathrm{O}^{2}\right)(\mathrm{py})_{2}\right]$ undergoes $\mathrm{OH}^{-}$substitution to form 
either $\left[\mathrm{Ru}{ }^{\mathrm{IV}}(\mathrm{OH})\left(\mathrm{tPa}-\kappa-\mathrm{N}^{2} \mathrm{O}\right)(\mathrm{py})_{2}\right]^{-}$or $\left[\mathrm{Ru}^{\mathrm{IV}}(\mathrm{O})\left(\mathrm{HtPa}-\kappa-\mathrm{N}^{2} \mathrm{O}\right)(\mathrm{py})_{2}\right]^{-}$. Further oxidation leads to the formation of highly reactive $\left[\mathrm{Ru}^{\mathrm{V}}(\mathrm{O})\left(\mathrm{tPa}-\kappa-\mathrm{N}^{2} \mathrm{O}\right)(\mathrm{py})_{2}\right]^{-}$species. The generation of the $\mathrm{Ru}^{\mathrm{IV}}-\mathrm{OH}$ (or $\mathrm{Ru}^{\mathrm{IV}}=\mathrm{O}$ ) occurs with the breaking of both the Ru-N and Ru-O bonds of one of the pyridylphosphonato arms of the $\mathrm{Pa}^{4-}$ ligand (Scheme 1). This is due to the steric congestion generated by the phosphonate group that precludes the formation of the CN7 complexes $\left[\mathrm{Ru}^{\mathrm{IV}}(\mathrm{O})(\mathrm{HtPa}-\mathrm{K}-\right.$ $\left.\left.\mathrm{N}^{3} \mathrm{O}\right)(\mathrm{py})_{2}\right]^{-}$and $\left[\mathrm{Ru}^{\mathrm{V}}(\mathrm{O})\left(\mathrm{tPa}-\kappa-\mathrm{N}^{3} \mathrm{O}\right)(\mathrm{py})_{2}\right]^{-}$. Once the highly reactive $\mathrm{Ru}^{\mathrm{V}}=\mathrm{O}$ species is generated then the dangling pyridyl-phosphonato arm has the perfect geometry to undergo intramolecular oxygen atom transfer to the non-coordinated pyridyl ring. This intramolecular O-atom insertion into the $\mathrm{CH}$ bond generates the catalytically active complex precursor $\left[\mathrm{Ru}^{\prime \prime \prime}\left(\mathrm{tPaO}-\mathrm{K}-\mathrm{N}^{2} \mathrm{O}_{\mathrm{P}} \mathrm{O}_{c}\right)(\mathrm{py})_{2}\right]^{2-}, \mathbf{4}^{\mathbf{2 -}}$.

Two electron oxidation of $4^{2-}$ forms the $\mathrm{Ru}^{\mathrm{V}}=\mathrm{O}$ species that performs $\mathrm{O}-\mathrm{O}$ bond formation via WNA and generates the $\mathrm{Ru}^{\mathrm{III}}-\mathrm{OOH}$ intermediate. This step is the rate-determining step (rds) of the catalytic cycle and is favored by the intramolecular proton transfer from the incoming water molecule to the phosphonate group that again has the right geometry to promote this step reducing the activation free energy. This renders $4^{2-}$ as an extremely powerful catalyst giving a $T O F_{\max }$ of $16,000 \mathrm{~s}^{-1}$ with an overpotential of $530 \mathrm{mV}$ at pH 7.0. It gives a higher $\operatorname{TOF}_{\max }\left(8.000 \mathrm{~s}^{-1}\right)$ than 1 at lower overpotential at $(75 \mathrm{mV}$.

In summary, the dangling phosphonate group is responsible for low energy pathway of the two key reactions: (i) The formation of active catalyst precursor $\left[\mathrm{Ru}^{\prime \prime \prime}\left(\mathrm{tPaO}-\kappa-\mathrm{N}^{2} \mathrm{O}_{\mathrm{p}} \mathrm{O}_{c}\right)(\mathrm{py})_{2}\right]^{2-}, \mathbf{4}^{2-}$, via oxygen insertion and (ii) the intramolecular proton transfer from the incoming water molecule for the O-O bond formation step that is the rds in the WNA mechanism. These two key reactions occur intramolecularly thanks to the right positioning of the $\mathrm{Ru}^{\mathrm{V}}=\mathrm{O}$ groups versus the dangling phosphonato group and thus are entropically highly favored.

The present work highlights the importance of designing catalysts with the right second coordination sphere environment in the field of redox catalysis and in particular in the catalytic oxidation of water to dioxygen and the fate of the catalysts during turnover.

4. Supporting Information. Additional experimental details, electrochemical and spectroscopic data are available free of charge via the Internet at http://pubs.acs.org. CIF files for complexes 
$\left\{\left[\mathrm{Ru}^{\prime \prime}\left(\mathrm{H}_{3} \mathrm{tPa}-\kappa-\mathrm{N}^{3} \mathrm{O}\right)(\mathrm{py})_{2}\right]\left(\mathrm{H}_{2} \mathrm{O}\right)_{3}\right\}\left(\mathrm{PF}_{6}\right)$ and $\left\{\left[\mathrm{Ru}^{\prime \prime}\left(\mathrm{tPaO}-\kappa-\mathrm{N}^{2} \mathrm{O}_{\mathrm{P}} \mathrm{O}_{\mathrm{c}}\right)(\mathrm{py})_{2}\right]\left(\mathrm{H}_{2} \mathrm{O}\right)_{8.5}\left(\mathrm{CH}_{3} \mathrm{OH}\right)\right\} \mathrm{Cs}_{3}$, with CCDC numbers 1890782 and 1954776 respectively are available at https://www.ccdc.cam.ac.uk/.

\section{Acknowledgments}

Support from MINECO, FEDER, "La Caixa" and AGAUR are gratefully acknowledged (CTQ201680058-R, CTQ2015-73028-EXP, SEV 2013-0319, ENE2016-82025-REDT, CTQ2016-81923-REDC, and 2017-SGR-1631). The work at Brookhaven National Laboratory (BNL; M.Z.E) was carried out under contract DE-SC0012704 with the U.S. Department of Energy, Office of Science, Office of Basic Energy Sciences, and utilized computational resources at the Center for Functional Nanomaterials, which is a U.S. DOE Office of Science Facility, and the Scientific Data and Computing Center, a component of the Computational Science Initiative, at BNL under Contract No. DE-SC0012704. 
Chart 1. Drawing and labeling of ligands discussed in this work.<smiles>O=C(O)c1cccc(-c2cccc(-c3cccc(C(=O)O)n3)n2)n1</smiles>

$\mathrm{H}_{2} \mathrm{tda}$<smiles>O=P(O)(O)c1cccc(-c2cccc(-c3cccc(P(=O)(O)O)n3)n2)n1</smiles>

$\mathrm{H}_{4} \mathrm{tPa}$<smiles>O=C(O)c1cccc(-c2cccc(C(=O)O)n2)n1</smiles>

$\mathrm{H}_{2} \mathrm{bda}$<smiles>O=P(O)(O)c1cccc(-c2cccc(-c3nc(P(=O)(O)O)ccc3O)n2)n1</smiles>

$\mathrm{H}_{5} \mathrm{tPaO}$ 
Scheme 1. Computed reaction pathway at pH 7.0 for the generation of the catalytically active species $\left[\mathrm{Ru}^{\prime \prime \prime}\left(\mathrm{tPaO}-\kappa-\mathrm{N}^{2} \mathrm{O}_{\mathrm{P}} \mathrm{O}_{\mathrm{c}}\right)(\mathrm{py})_{2}\right]^{2-}, \mathbf{4}^{2-}$, from the precursor complex $\left[\mathrm{Ru}^{\prime \prime}\left(\mathrm{H}_{2} \mathrm{tPa}-\kappa-\mathrm{N}^{3} \mathrm{O}\right)(\mathrm{py})_{2}\right], \mathbf{2}$. Redox potentials (E) in units of volts (V) vs NHE, $\Delta G s$, and $\Delta G^{\ddagger}$ in units of $\mathrm{kcal} / \mathrm{mol}$. Axial pyridyl ligands are omitted for clarity.

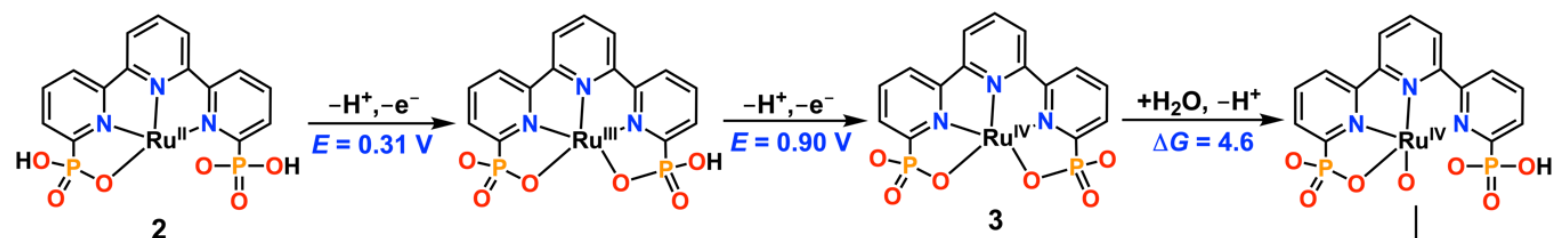
2

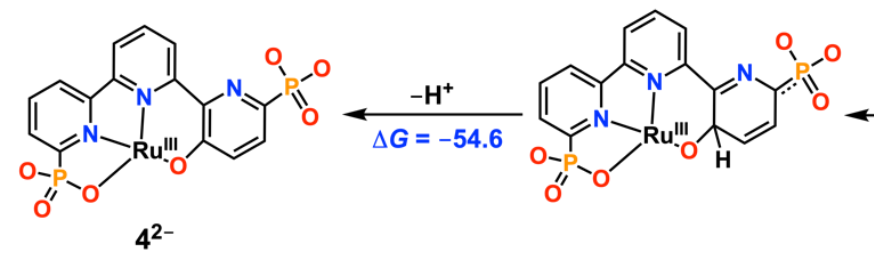

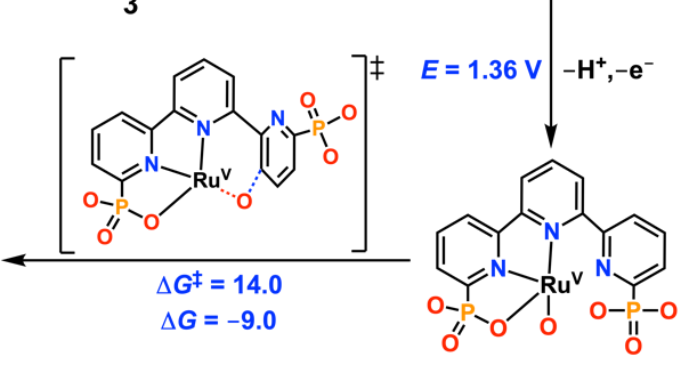


Figure 1. Synthetic scheme and structures of the complexes described in this work. X-ray structure ORTEP views for $\left\{\left[\mathrm{Ru}^{\prime \prime}\left(\mathrm{H}_{3} \mathrm{tPa}-\kappa-\mathrm{N}^{3} \mathrm{O}\right)(\mathrm{py})_{2}\right]\left(\mathrm{H}_{2} \mathrm{O}\right)_{3}\right\}^{+}, \mathbf{2}^{+} \cdot 3 \mathrm{H}_{2} \mathrm{O}$, showing the 3 hydrogen bonded water molecules and for $\left[\mathrm{Ru}^{\prime \prime \prime}\left(\mathrm{tPaO}-\kappa-\mathrm{N}^{2} \mathrm{O}_{\mathrm{p}} \mathrm{O}_{\mathrm{c}}\right)(\mathrm{py})_{2}\right]^{2-}, 4^{2-}$. Calculated structure for $\left[\mathrm{Ru}^{\mathrm{IV}}\left(\mathrm{tPa}-\kappa^{-} \mathrm{N}^{3} \mathrm{O}^{2}\right)(\mathrm{py})_{2}\right]$, 3. Color code: Ru, cyan; P, pink; N, blue; O, red; C, black; $H$, white.

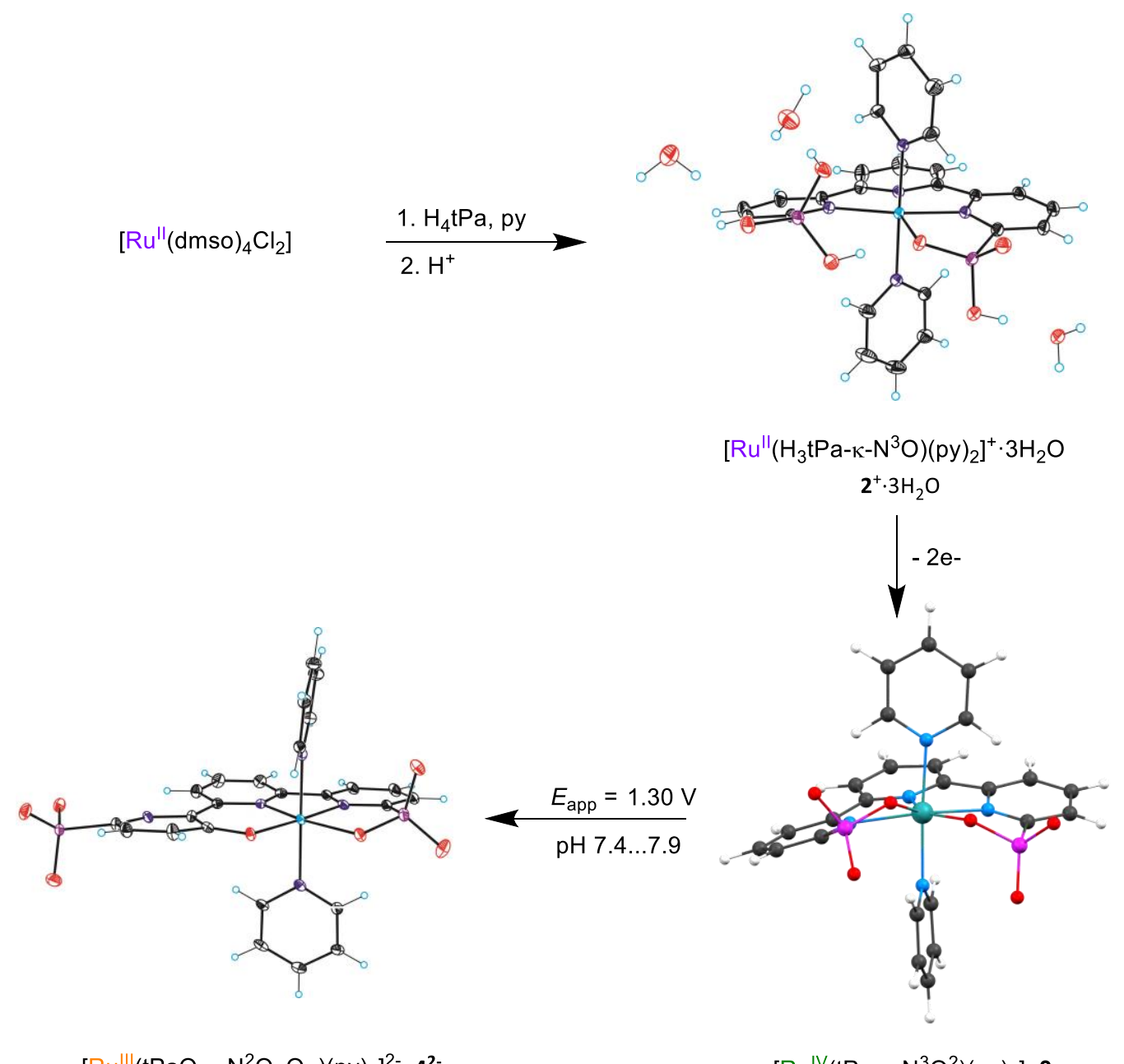

$\left[\mathrm{Ru} \mathrm{u}^{\prime \prime \prime}\left(\mathrm{tPaO}-\kappa-\mathrm{N}^{2} \mathrm{O}_{\mathrm{P}} \mathrm{O}_{\mathrm{C}}\right)(\mathrm{py})_{2}\right]^{2-}, 4^{2-}$

$\left[\mathrm{Ru}^{\mathrm{IV}}\left(\mathrm{tPa}-\kappa-\mathrm{N}^{3} \mathrm{O}^{2}\right)(\mathrm{py})_{2}\right], 3$ 
Figure 2. VT ${ }^{1} \mathrm{H}-\mathrm{NMR}$ of $\left[\mathrm{Ru} \mathrm{u}^{\prime \prime}\left(\mathrm{H}_{2} \mathrm{tPa}-\kappa-\mathrm{N}^{3} \mathrm{O}\right)(\mathrm{py})_{2}\right], 2$ in $\mathrm{CD}_{3} \mathrm{OD}$ together with labeling.

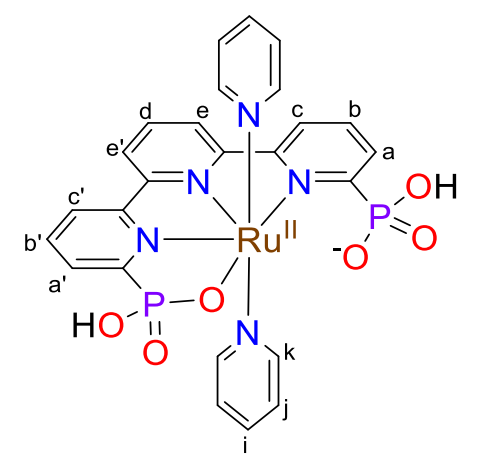

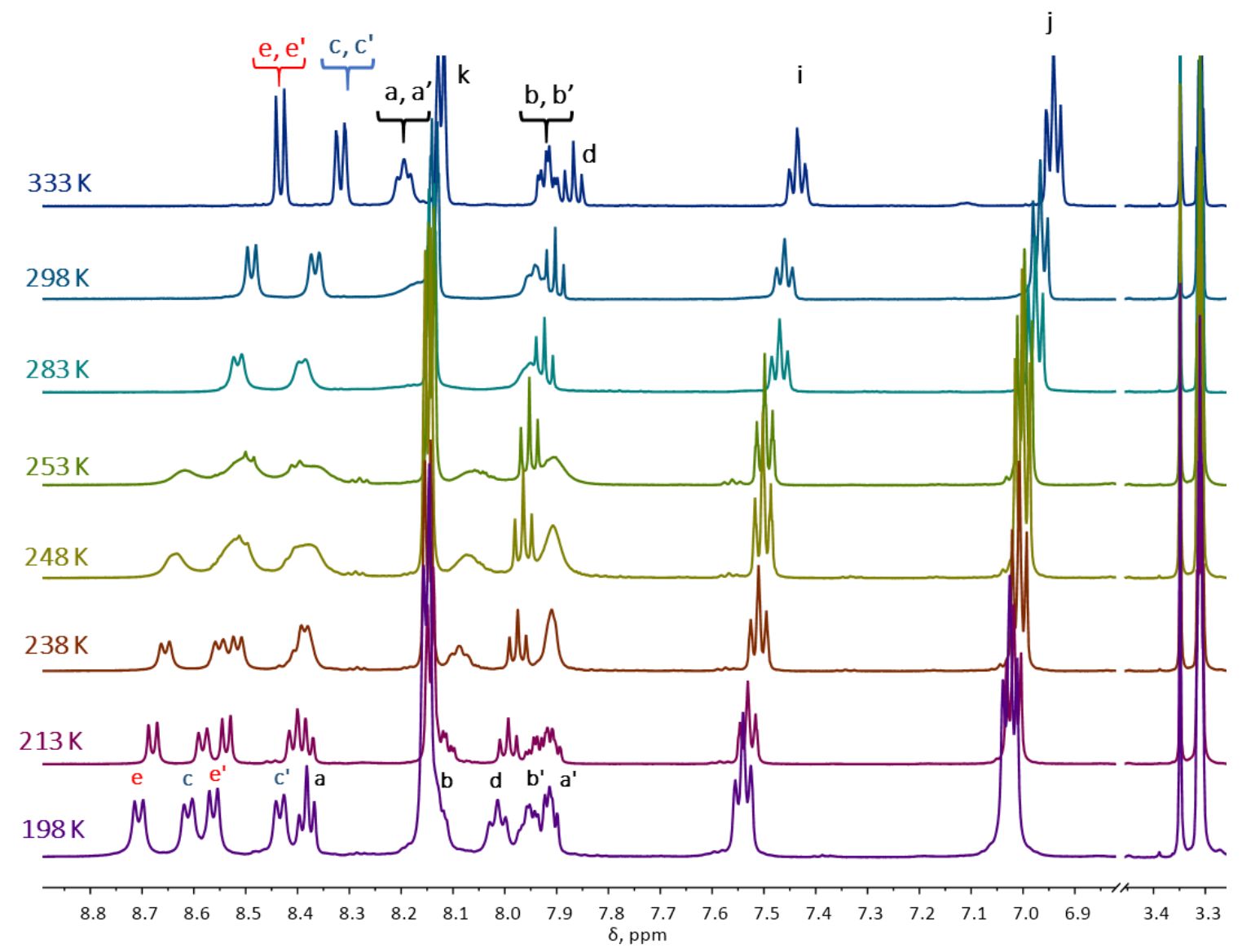


Figure 3. Left, cyclic voltammetry of $0.6 \mathrm{mM}\left[\mathrm{Ru}^{\prime \prime}\left(\mathrm{HtPa}-\kappa-\mathrm{N}^{3} \mathrm{O}\right)(\mathrm{py})_{2}\right]^{-}, \mathbf{2}^{-}$, at $\mathrm{pH} 7.0$ in a $0.1 \mathrm{M}$ phosphate buffer aqueous solution (red trace) and at pH = 1.0 in $0.1 \mathrm{M}$ triflic acid (purple trace). Solid line black trace, cyclic voltammetry of $0.6 \mathrm{mM}\left[\mathrm{Ru}{ }^{\prime \prime \prime}\left(\mathrm{tPaO}-\kappa-\mathrm{N}^{2} \mathrm{O}_{\mathrm{P}} \mathrm{O}_{c}\right)(\mathrm{py})_{2}\right]^{2-}, 4^{2-}$, at pH 7.0 in a $0.1 \mathrm{M}$ phosphate buffer aqueous solution, generated from the precursor $2^{-}$, by a $3 \mathrm{~h}$ bulk electrolysis at $1.30 \mathrm{~V}$. Right, Pourbaix diagram for $\mathbf{2}$. The dominant species as a function of $\mathrm{pH}$ and potential are indicated with the labels such as $\left[\mathrm{Ru}^{\prime \prime}\left(\mathrm{H}_{2} \mathrm{tPa}\right)\right]$ where the oxidation state is indicated as well as the degree of protonation of the $\mathrm{H}_{4} \mathrm{tPa}$ ligand. The dashed vertical lines indicate the $\mathrm{p} K_{\mathrm{a}}$ of the species involved. The axial pyridyl ligands are omitted for clarity.
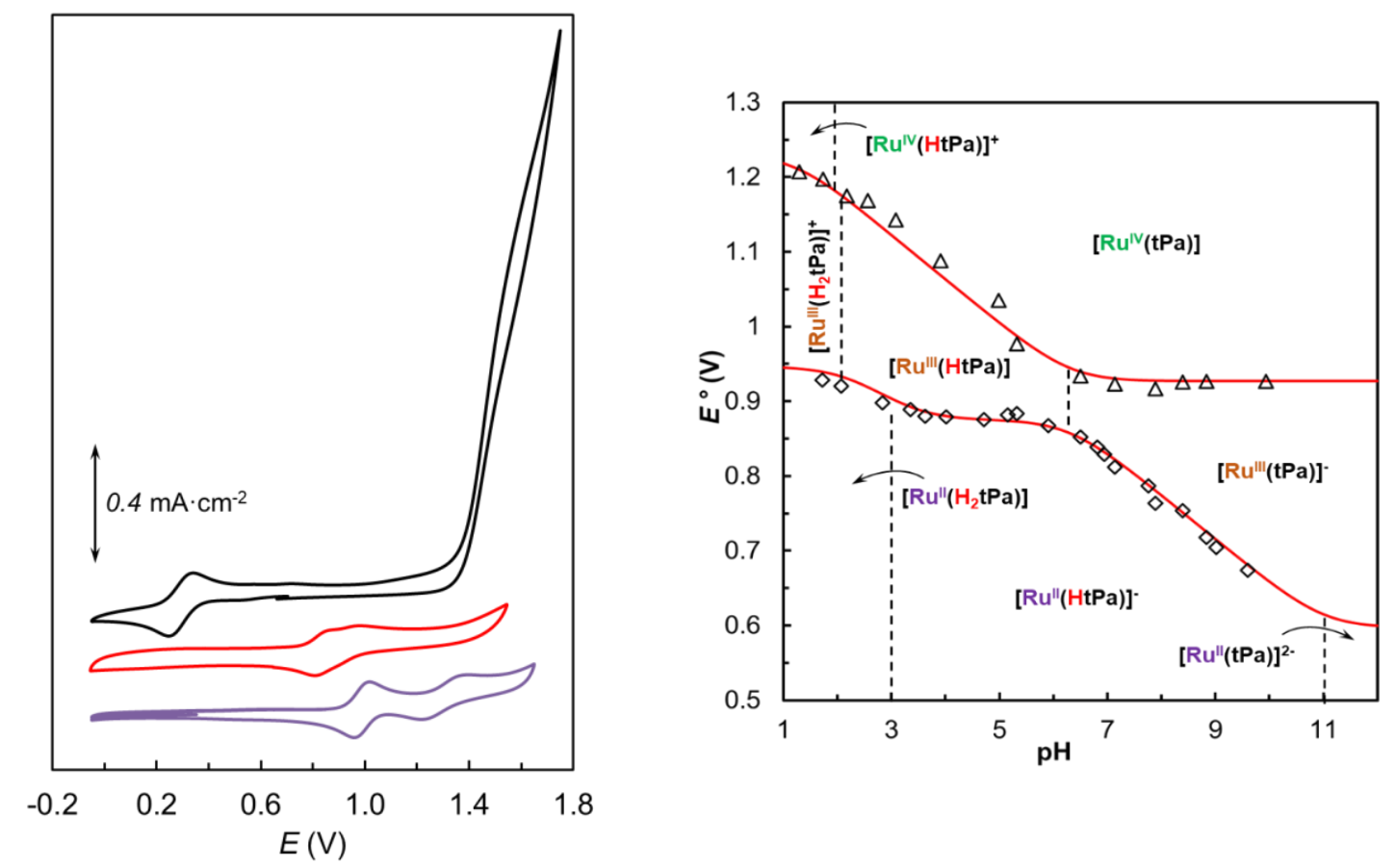
Figure 4. Top, calculated catalytic cycle for catalyst $\left[\mathrm{Ru}^{\mathrm{V}}(\mathrm{O})\left(\mathrm{HtPaO}-\mathrm{\kappa}^{-}-\mathrm{N}^{2} \mathrm{O}_{\mathrm{c}}\right)(\mathrm{py})_{2}\right]^{-}$at $\mathrm{pH} 7.0 \mathrm{Redox}$ potentials (E) (experimental in green and calculated in blue) in units of volts (V) vs NHE, $\Delta G$ s and $\Delta G^{\ddagger}$ in units of $\mathrm{kcal} / \mathrm{mol}$. Axial pyridyl ligands are omitted for clarity. Bottom, optimized TS for the $\mathrm{O}-\mathrm{O}$ bond formation step. Color code: Ru, cyan; P, orange; $\mathrm{N}$, blue; $\mathrm{O}$, red; C, black; $\mathrm{H}$, white.
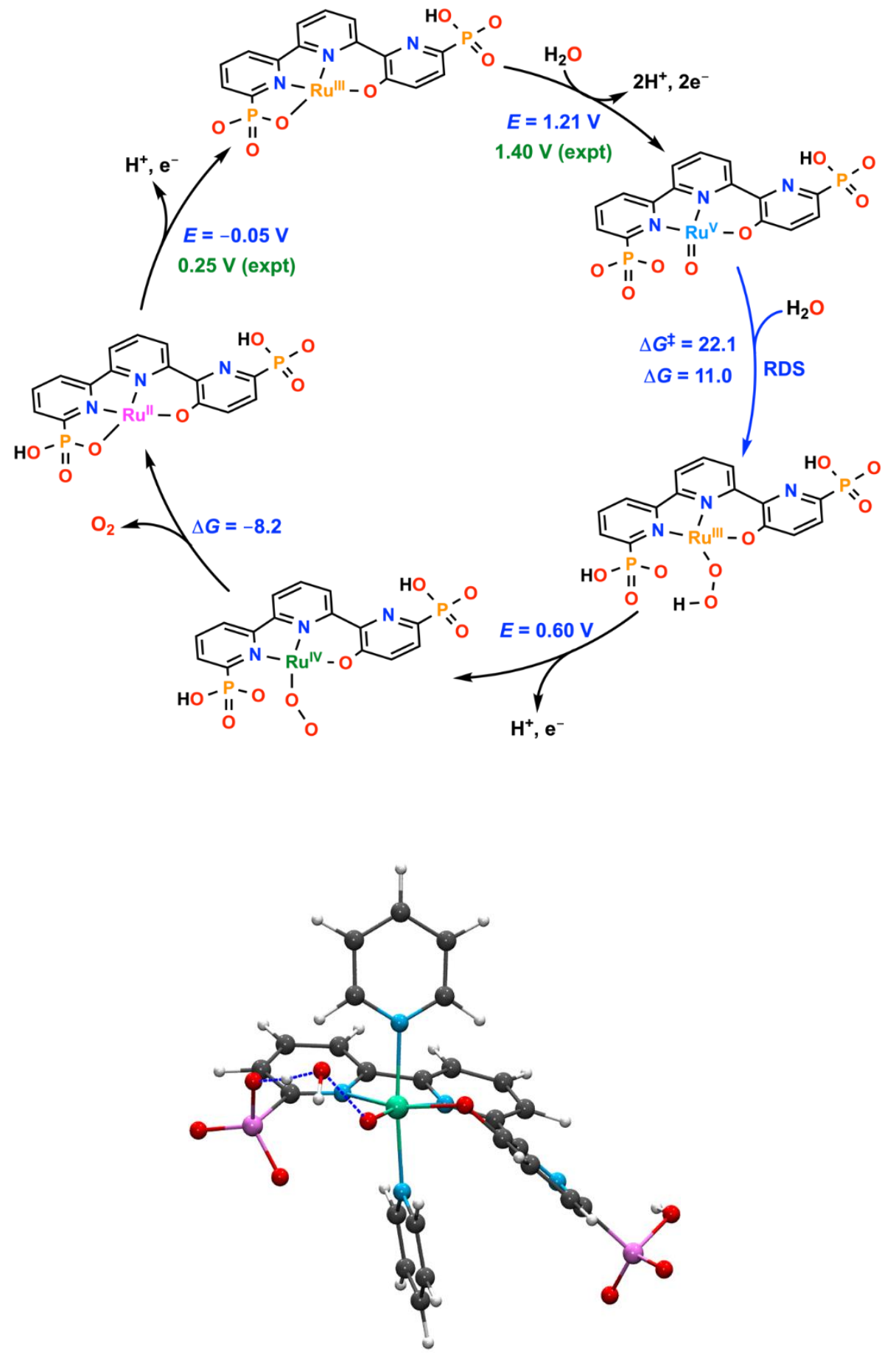
(1) Berardi, S.; Drouet, S.; Francàs, L.; Gimbert-Suriñach, C.; Guttentag, M.; Richmond, C.; Stoll, T.; Llobet, A. Molecular Artificial Photosynthesis. Chem. Soc. Rev. 2014, 43 (22), 7501-7519.

(2) Lewis, N. S. Research Opportunities to Advance Solar Energy Utilization. Science (80-. ). 2016, 351 (6271), aad1920.

(3) Alstrum-Acevedo, J. H.; Brennaman, M. K.; Meyer, T. J. Chemical Approaches to Artificial Photosynthesis. 2. Inorg. Chem. 2005, 44 (20), 6802-6827.

(4) Kärkäs, M. D.; Johnston, E. V; Verho, O.; Åkermark, B. Artificial Photosynthesis: From Nanosecond Electron Transfer to Catalytic Water Oxidation. Acc. Chem. Res. 2014, 47 (1), 100-111.

(5) Cook, T. R.; Dogutan, D. K.; Reece, S. Y.; Surendranath, Y.; Teets, T. S.; Nocera, D. G. Solar Energy Supply and Storage for the Legacy and Nonlegacy Worlds. Chem. Rev. 2010, 110 (11), 6474-6502.

(6) Walter, M. G.; Warren, E. L.; McKone, J. R.; Boettcher, S. W.; Mi, Q.; Santori, E. A.; Lewis, N. S. Solar Water Splitting Cells. Chem. Rev. 2010, 110 (11), 6446-6473.

(7) De Luna, P.; Hahn, C.; Higgins, D.; Jaffer, S. A.; Jaramillo, T. F.; Sargent, E. H. What Would It Take for Renewably Powered Electrosynthesis to Displace Petrochemical Processes? Science (80-. ). 2019, 364 (6438), eaav3506.

(8) Garrido-Barros, P.; Gimbert-Suriñach, C.; Matheu, R.; Sala, X.; Llobet, A. How to Make an Efficient and Robust Molecular Catalyst for Water Oxidation. Chem. Soc. Rev. 2017, 46 (20), 6088-6098.

(9) Matheu, R.; Garrido-Barros, P.; Gil-Sepulcre, M.; Ertem, M. Z.; Sala, X.; Gimbert-Suriñach, C.; Llobet, A. The Development of Molecular Water Oxidation Catalysts. Nat. Rev. Chem. 2019, 3 (5), 331-341.

(10) Sala, X.; Maji, S.; Bofill, R.; García-Antón, J.; Escriche, L.; Llobet, A. Molecular Water Oxidation Mechanisms Followed by Transition Metals: State of the Art. Acc. Chem. Res. 2014, 47 (2), 504-516.

(11) Gimbert-Suriñach, C.; Moonshiram, D.; Francàs, L.; Planas, N.; Bernales, V.; Bozoglian, F.; Guda, A.; Mognon, L.; López, I.; Hoque, M. A.; Gagliardi, L.; Cramer, C. J.; Llobet, A. Structural and Spectroscopic Characterization of Reaction Intermediates Involved in a Dinuclear CoHbpp Water Oxidation Catalyst. J. Am. Chem. Soc. 2016, 138 (47), 15291-15294.

(12) Romain, S.; Bozoglian, F.; Sala, X.; Llobet, A. Oxygen-Oxygen Bond Formation by the Ru-Hbpp Water Oxidation Catalyst Occurssolely via an Intramolecular Reaction Pathway. J. Am. Chem. Soc. 2009, 131 (8), 2768-2769.

(13) Shaffer, D. W.; Xie, Y.; Concepcion, J. J. O-O Bond Formation in Ruthenium-Catalyzed Water Oxidation: Single-Site Nucleophilic Attack vs. O-O Radical Coupling. Chem. Soc. Rev. 2017, 46 (20), 6170-6193.

(14) Wang, L. P.; Van Voorhis, T. Direct-Coupling O2 Bond Forming a Pathway in Cobalt Oxide Water Oxidation Catalysts. J. Phys. Chem. Lett. 2011, 2 (17), 2200-2204.

(15) McCrory, C. C. L.; Jung, S.; Ferrer, I. M.; Chatman, S. M.; Peters, J. C.; Jaramillo, T. F. Benchmarking Hydrogen Evolving Reaction and Oxygen Evolving Reaction Electrocatalysts for Solar Water Splitting Devices. J. Am. Chem. Soc. 2015, 137 (13), 4347-4357.

(16) Hong, W. T.; Stoerzinger, K. A.; Lee, Y. L.; Giordano, L.; Grimaud, A.; Johnson, A. M.; Hwang, J.; Crumlin, E. J.; Yang, W.; Shao-Horn, Y. Charge-Transfer-Energy-Dependent Oxygen Evolution Reaction Mechanisms for Perovskite Oxides. Energy Environ. Sci. 2017, 10 (10), 2190-2200.

(17) Surendranath, Y.; Kanan, M. W.; Nocera, D. G. Mechanistic Studies of the Oxygen Evolution Reaction by a Cobalt-Phosphate Catalyst at Neutral PH. J. Am. Chem. Soc. 2010, 132 (46), 16501-16509. 
(18) Matheu, R.; Ertem, M. Z.; Gimbert-Suriñach, C.; Sala, X.; Llobet, A. Seven Coordinated Molecular Ruthenium-Water Oxidation Catalysts: A Coordination Chemistry Journey. Chem. Rev. 2019, 119 (6), 3453-3471.

(19) Matheu, R.; Ertem, M. Z.; Benet-Buchholz, J.; Coronado, E.; Batista, V. S.; Sala, X.; Llobet, A. Intramolecular Proton Transfer Boosts Water Oxidation Catalyzed by a Ru Complex. J. Am. Chem. Soc. 2015, 137 (33), 10786-10795.

(20) Richmond, C. J.; Matheu, R.; Poater, A.; Falivene, L.; Benet-Buchholz, J.; Sala, X.; Cavallo, L.; Llobet, A. Supramolecular Water Oxidation with Rubda-Based Catalysts. Chem. - A Eur. J. 2014, 20 (52), 17282-17286.

(21) Duan, L.; Bozoglian, F.; Mandal, S.; Stewart, B.; Privalov, T.; Llobet, A.; Sun, L. A Molecular Ruthenium Catalyst with Water-Oxidation Activity Comparable to That of Photosystem II. Nat. Chem. 2012, 4 (5), 418-423.

(22) Song, N.; Concepcion, J. J.; Binstead, R. A.; Rudd, J. A.; Vannucci, A. K.; Dares, C. J.; Coggins, M. K.; Meyer, T. J. Base-Enhanced Catalytic Water Oxidation by a Carboxylate-Bipyridine Ru(II) Complex. Proc. Natl. Acad. Sci. 2015, 112 (16), 4935-4940.

(23) Xie, Y.; Shaffer, D. W.; Lewandowska-Andralojc, A.; Szalda, D. J.; Concepcion, J. J. Water Oxidation by Ruthenium Complexes Incorporating Multifunctional Bipyridyl Diphosphonate Ligands. Angew. Chemie - Int. Ed. 2016, 55 (28), 8067-8071.

(24) Kamdar, J. M.; Marelius, D. C.; Moore, C. E.; Rheingold, A. L.; Smith, D. K.; Grotjahn, D. B. Ruthenium Complexes of 2,2'-Bipyridine-6,6'-Diphosphonate Ligands for Water Oxidation. ChemCatChem 2016, 8 (19), 3045-3049.

(25) Shaffer, D. W.; Xie, Y.; Szalda, D. J.; Concepcion, J. J. Lability and Basicity of BipyridineCarboxylate-Phosphonate Ligand Accelerate Single-Site Water Oxidation by RutheniumBased Molecular Catalysts. J. Am. Chem. Soc. 2017, 139 (43), 15347-15355.

(26) Surendranath, Y.; Dincă, M.; Nocera, D. G. Electrolyte-Dependent Electrosynthesis and Activity of Cobalt-Based Water Oxidation Catalysts. J. Am. Chem. Soc. 2009, 131 (7), 26152620.

(27) Matheu, R.; Ertem, M. Z.; Gimbert-Suriñach, C.; Benet-Buchholz, J.; Sala, X.; Llobet, A. Hydrogen Bonding Rescues Overpotential in Seven-Coordinated Ru Water Oxidation Catalysts. ACS Catal. 2017, 7 (10), 6525-6532.

(28) Zoń, J.; Garczarek, P.; Białek, M. Chapter 6 Synthesis of Phosphonic Acids and Their Esters as Possible Substrates for Reticular Chemistry. In Metal Phosphonate Chemistry: From Synthesis to Applications; Clearfield, A., Demadis, K., Eds.; The Royal Society of Chemistry, London, 2012; pp 170-191.

(29) Hammes-Schiffer, S. Catalysts by Design: The Power of Theory. Acc. Chem. Res. 2017, 50 (3), 561-566.

(30) Meyer, T. J.; Sheridan, M. V.; Sherman, B. D. Mechanisms of Molecular Water Oxidation in Solution and on Oxide Surfaces. Chem. Soc. Rev. 2017, 46 (20), 6148-6169.

(31) Huynh, M. H. V.; Meyer, T. J. Proton-Coupled Electron Transfer. Chem. Rev. 2007, 107 (11), 5004-5064.

(32) Weinberg, D. R.; Gagliardi, C. J.; Hull, J. F.; Murphy, C. F.; Kent, C. A.; Westlake, B. C.; Paul, A.; Ess, D. H.; McCafferty, D. G.; Meyer, T. J. Proton-Coupled Electron Transfer. Chem. Rev. 2012, 112 (7), 4016-4093.

(33) Warren, J. J.; Tronic, T. A.; Mayer, J. M. Thermochemistry of Proton-Coupled Electron Transfer Reagents and Its Implications. Chem. Rev. 2010, 110 (12), 6961-7001.

(34) Shaffer, D. W.; Xie, Y.; Concepcion, J. J. O-O Bond Formation in Ruthenium-Catalyzed Water Oxidation: Single-Site Nucleophilic Attack: Vs. O-O Radical Coupling. Chem. Soc. Rev. 2017, 46 (20), 6170-6193. 
(35) Hammes-Schiffer, S.; Soudackov, A. V. Proton-Coupled Electron Transfer in Solution, Proteins, and Electrochemistry. J. Phys. Chem. B 2008, 112 (45), 14108-14123.

(36) Laurent, F.; Plantalech, E.; Donnadieu, B.; Jiménez, A.; Hernández, F.; Martínez-Ripoll, M.; Biner, M.; Llobet, A. Synthesis, Structure and Redox Properties of Ruthenium Complexes Containing the Tpm Facial and the Trpy Meridional Tridentate Ligands: Crystal Structures of $\left[\mathrm{RuCl}_{3}(\mathrm{Trpy})\right]$ and $\left[\mathrm{Ru}(\mathrm{Tpm})(\mathrm{Py})_{3}\right]\left(\mathrm{PF}_{6}\right)_{2}$. Polyhedron 1999, 18 (25), 3321-3331.

(37) Kuppuraj, G.; Dudev, M.; Lim, C. Factors Governing Metal-Ligand Distances and Coordination Geometries of Metal Complexes. J. Phys. Chem. B 2009, 113 (9), 2952-2960.

(38) Zhao, Y.; Truhlar, D. G. The M06 Suite of Density Functionals for Main Group Thermochemistry, Thermochemical Kinetics, Noncovalent Interactions, Excited States, and Transition Elements: Two New Functionals and Systematic Testing of Four M06-Class Functionals and 12 Other Function. Theor. Chem. Acc. 2008, 120 (1), 215-241.

(39) Marenich, A. V; Cramer, C. J.; Truhlar, D. G. Supporting Information ( PART I ) Universal Solvation Model Based on Solute Electron Density and on a Continuum Model of the Solvent Defined by the Bulk Dielectric Constant and Atomic Surface Tensions Contents: J. Phys. Chem. B 2009, 113, 6378.

(40) Hoque, M. A.; Benet-Buchholz, J.; Llobet, A.; Gimbert-Suriñach, C. Catalytic Oxidation of Water to Dioxygen by Mononuclear Ru Complexes Bearing a 2,6-Pyridinedicarboxylato Ligand. ChemSusChem 2019, 12 (9), 1949-1957.

(41) Matheu, R.; Ertem, M. Z.; Pipelier, M.; Lebreton, J.; Dubreuil, D.; Benet-Buchholz, J.; Sala, X.; Tessier, A.; Llobet, A. The Role of Seven-Coordination in Ru-Catalyzed Water Oxidation. ACS Catal. 2018, 8 (3), 2039-2048.

(42) Matheu, R.; Ghaderian, A.; Francàs, L.; Chernev, P.; Ertem, M. Z.; Benet-Buchholz, J.; Batista, V. S.; Haumann, M.; Gimbert-Suriñach, C.; Sala, X.; Llobet, A. Behavior of Ru-Bda WaterOxidation Catalysts in Low Oxidation States. Chem. - A Eur. J. 2018, 24 (49), 12838-12847.

(43) Brauman, J. I.; Bryson, J. A.; Kahl, D. C.; Nelson, N. J. Equilibrium Acidities in Dimethyl Sulfoxide. J. Am. Chem. Soc. 1970, 92 (22), 6679-6680.

(44) Nazeeruddin, M. K.; Zakeeruddin, S. M.; Humphry-Baker, R.; Kaden, T. A.; Grätzel, M. Determination of PKa Values of 4-Phosphonato-2,2':6',2 ' '-Terpyridine and Its Ruthenium(II)Based Photosensitizer by NMR, Potentiometric, and Spectrophotometric Methods. Inorg. Chem. 2000, 39 (20), 4542-4547.

(45) Ordóñez, M.; Viveros-Ceballos, J. L.; Sayago, F. J.; Cativiela, C. Stereoselective Synthesis of $\alpha-$ Amino- H -Phosphinic Acids and Derivatives. Synth. 2017, 49 (5), 987-997.

(46) Becker, M.; Schindler, S.; Karlin, K. D.; Kaden, T. A.; Kaderli, S.; Palanché, T.; Zuberbühler, A. D. Intramolecular Ligand Hydroxylation: Mechanistic High-Pressure Studies on the Reaction of a Dinuclear Copper(I) Complex with Dioxygen. Inorg. Chem. 1999, 38 (9), 1989-1995.

(47) Costentin, C.; Drouet, S.; Robert, M.; Savéant, J.-M. Turnover Numbers, Turnover Frequencies, and Overpotential in Molecular Catalysis of Electrochemical Reactions. Cyclic Voltammetry and Preparative-Scale Electrolysis. J. Am. Chem. Soc. 2012, 134 (27), 1123511242.

(48) Rountree, E. S.; McCarthy, B. D.; Eisenhart, T. T.; Dempsey, J. L. Evaluation of Homogeneous Electrocatalysts by Cyclic Voltammetry. Inorg. Chem. 2014, 53 (19), 9983-10002.

(49) Matheu, R.; Neudeck, S.; Meyer, F.; Sala, X.; Llobet, A. Foot of the Wave Analysis for Mechanistic Elucidation and Benchmarking Applications in Molecular Water Oxidation Catalysis. ChemSusChem 2016, 9 (23), 3361-3369.

(50) Wasylenko, D. J.; Ganesamoorthy, C.; Henderson, M. A.; Koivisto, B. D.; Osthoff, H. D.; Berlinguette, C. P. Electronic Modification of the $\left[\text { Rull(Tpy)(Bpy) }\left(\mathrm{OH}_{2}\right)\right]^{2+}$ Scaffold: Effects on Catalytic Water Oxidation. J. Am. Chem. Soc. 2010, 132 (45), 16094-16106. 
(51) Zhao, Y.; Truhlar, D. G. A New Local Density Functional for Main-Group Thermochemistry, Transition Metal Bonding, Thermochemical Kinetics, and Noncovalent Interactions. J. Chem. Phys. 2006, 125 (19), 194101.

(52) Zhan, S.; De Gracia Triviño, J. A.; Ahlquist, M. S. G. The Carboxylate Ligand as an Oxide Relay in Catalytic Water Oxidation. J. Am. Chem. Soc. 2019, 141 (26), 10247-10252.

(53) Wang, J. W.; Sahoo, P.; Lu, T. B. Reinvestigation of Water Oxidation Catalyzed by a Dinuclear Cobalt Polypyridine Complex: Identification of CoOxas a Real Heterogeneous Catalyst. ACS Catal. 2016, 6 (8), 5062-5068.

(54) Matheu, R.; Ertem, M. Z.; Gimbert-Suriñach, C.; Sala, X.; Llobet, A. Seven Coordinated Molecular Ruthenium-Water Oxidation Catalysts: A Coordination Chemistry Journey. Chem. Rev. 2019, 119 (6), 3453-3471.

(55) Moyer, B. A.; Thompson, M. S.; Meyer, T. J. Chemically Catalyzed Net Electrochemical Oxidation of Alcohols, Aldehydes, and Unsaturated Hydrocarbons Using the System (Trpy)(Bpy)Ru(OH $)^{2+} /\left(\right.$ Trpy)(Bpy)RuO ${ }^{2+}$. J. Am. Chem. Soc. 1980, 102 (7), 2310-2312.

(56) Wasylenko, D. J.; Ganesamoorthy, C.; Henderson, M. A.; Koivisto, B. D.; Osthoff, H. D.; Berlinguette, C. P. Supporting Information: Electronic Modification of the [Ru II (Tpy)(Bpy) $\left.\left(\mathrm{OH}_{2}\right)\right]$ 2+ Scaffold: Effects on Catalytic Water Oxidation. J. Am. Chem. Soc. 2010, 132 (45), 16094-16106.

(57) López, I.; Maji, S.; Benet-Buchholz, J.; Llobet, A. Oxo-Bridge Scenario behind Single-Site Water-Oxidation Catalysts. Inorg. Chem. 2015, 54 (2), 658-666.

(58) Takeuchi, K. J.; Thompson, M. S.; Pipes, D. W.; Meyer, T. J. Redox and Spectral Properties of Monooxo Polypyridyl Complexes of Ruthenium and Osmium in Aqueous Media. Inorg. Chem. 1984, 23 (13), 1845-1851. 
TOC

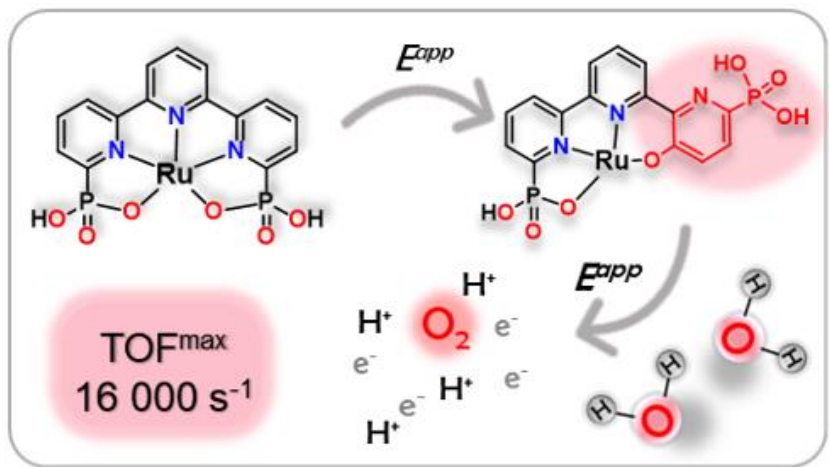

